Tropical Journal of Pharmaceutical Research, December 2006; 5 (2): 589-596

(C) Pharmacotherapy Group,

Faculty of Pharmacy, University of Benin

Benin City, Nigeria.

All rights reserved.

Available online at http://www.tjpr.freehosting.net

Research Article

\title{
Compression, Mechanical and Release Properties of Chloroquine Phosphate Tablets containing corn and Trifoliate Yam Starches as Binders
}

\author{
Oladapo A. Adetunji, Michael A. Odeniyi and Oludele A. Itiola * \\ Department of Pharmaceutics \& Industrial Pharmacy, Faculty of Pharmacy, University of Ibadan, Nigeria.
}

\begin{abstract}
Purpose: A study was made of the binding properties of trifoliate yam starch, obtained from Dioscorea dumetorum (Pax), in chloroquine phosphate tablet formulations in comparison with official corn starch.

Method: Compressional properties were analyzed using density measurements and compression equations of Heckel and Kawakita. The mechanical properties of the tablets were assessed using the crushing strength and friability of the tablets, while drug release properties of the tablets were assessed using disintegration and dissolution times.

Results: Tablet formulations containing trifoliate yam starch exhibited faster onset and higher amount of plastic deformation during compression than those containing corn starch. The crushing strength, disintegration and dissolution times of the tablets increased with binder concentration while friability values decreased. Trifoliate yam starch produced tablets with stronger mechanical properties and longer disintegration and dissolution times than those containing corn starch.

Conclusion: Trifoliate yam starch would be a better alternative to corn starch in producing uncoated tablets for which high bond strength is essential.
\end{abstract}

Keywords: Trifoliate yam starch, corn starch, binding agent, compression, Heckel equation, Kawakita equation, mechanical properties, drug release.

*Corresponding Author: E-mail: oprofit@yahoo.com 


\section{INTRODUCTION}

A survey of the literature shows that the usefulness of starches from various botanical sources as pharmaceutical excipients has formed a subject of interesting study for close to four decades ${ }^{1-5}$. Starches are widely available and have been very useful in tablet production due to their inertness, cheapness and utilization as fillers, binders, disintegrants and glidants ${ }^{6,7}$.

Many starches obtained from different food crops have shown enough potential as excipients in tablet formulations to stimulate further research and development efforts. In this regard, a lot of efforts have been expended to develop locally produced starches as binders and disintegrants ${ }^{8}$. Nasipuri evaluated the use of Dioscorea rotundata as a binder and disintegrant in tablet formulation ${ }^{1}$ and Itiola also investigated the compressional properties of this particular starch ${ }^{9}$. However, little work has been done to evaluate the effects of trifoliate yam starch obtained from Dioscorea dumetorum (Pax) on the compressional, mechanical and release properties of tablet formulations.

The Heckel equation is widely used for relating the relative density, $D$, of a powder bed during compression to the applied pressure, $P^{10,11}$. It is written as:

$\ln [1 /(1-D)]=K P+A$

where $\mathrm{K}$ and $\mathrm{A}$ are constants.

The Heckel equation is a sensitive tool to study the compressibility of materials. It describes the relationship of the compact density to the applied pressure. The slope of the straight line portion, $\mathrm{K}$, is the reciprocal of the mean yield pressure, $P_{y}$, of the material. The intercept of the extrapolated linear portion, $A$, is a function of the original compact volume.

From the value of $A$, the relative Density $\left(D_{A}\right)$ can be calculated using the following equation.

$D_{A}=1-e^{-A}$

The relative density of the powder bed at the point when the applied pressure equals zero, $D_{0}$, is used to describe the initial rearrangement phase of densification as a result of die filling and this is obtained from the ratio of the loose density to the particle density. The relative Density, $D_{B}$, describes the phase of rearrangement of particles during the initial stages of compression. The extent of rearrangement phase depends on the theoretical point of densification at which deformation of particles begins.

Thus, $D_{B}=D_{A}-D_{0}$

The Kawakita equation ${ }^{13}$ is used to study of powder compression using the degree of volume reduction $(\mathrm{C})$ and is written as:

$$
\begin{gathered}
C=(V o-V p) / V o=a b P /(1+b P) \\
\text { The equation in practice can be }
\end{gathered}
$$
rearranged as:

$$
P / C=(P / a)+(1 / a b)
$$

in which $V_{0}$ is the powder's initial bulk volume and $V_{p}$ is the bulk volume after compression. The constant, ' $a$ ' is the material's minimum porosity before compression while the constant ' $b$ ' relates to the material's plasticity. The reciprocal of $b$ defines a pressure term $P_{k}$, which is the pressure required to reduce the powder bed by $50 \%{ }^{14,15}$.

Thus, the present study was designed to evaluate the effects of trifoliate yam starch as a binder in a chloroquine phosphate tablet formulation in comparison to official corn starch BP grade.

Chloroquine phosphate was chosen for the work because of its poor tableting properties and hence requires a binder among other excipients to form satisfactory tablets.

\section{MATERIALS AND METHODS}

\section{Materials}

The materials used were chloroquine phosphate powder (product of People's Republic of China, made to the specification of BP 1988, and supplied by Bentos Pharmaceutical Products Ltd., Nigeria), corn starch BP (Lot 69833 supplied by Bentos Pharmaceutical Products Ltd., Nigeria), Lactose B. P (DVM Veghel, Holland) and Trifoliate (Wild) yam starch obtained from the tubers of Dioscorea dumetorum (Pax). The experimental starch was prepared in a University of Ibadan laboratory. 
The description of the preparation and purification of the starches have been given elsewhere ${ }^{12}$. The particle density of granules was determined by the pycnometer method using xylene as the displacement fluid

\section{Preparation of granules}

$250 \mathrm{~g}$ batches of a basic formulation comprising of chloroquine $(60 \% \mathrm{w} / \mathrm{w})$, Lactose $(30 \% \mathrm{w} / \mathrm{w})$ and corn - starch $(10 \% \mathrm{w} / \mathrm{w})$ were dry mixed for about five minutes in a Kenwood planetary mixer. The mixture was then moistened with appropriate amount of pastes of the binding agent (Wild yam, Dioscorea dumetorum starch or and corn starch) to produce samples containing 2.5, 5.0, 7.5 and $10.0 \% \mathrm{w} / \mathrm{w}$ of the binders.

Massing was continued for about five minutes and the wet masses were granulated by passing them manually through a NO 12 mesh sieve $(1,400 \mu \mathrm{m})$. The granules were dried in a hot air oven for 24 hours at $60^{\circ} \mathrm{C}$ and then resieved through a N0 16 mesh sieve $(1,000 \mu \mathrm{m})$, before they were stored in air - tight containers.

\section{Determination of pre-compression pressure}

The bulk density of each formulation at zero pressure (loose density) was determined by pouring the granules into a $50 \mathrm{ml}$ glass measuring cylinder with a diameter of $24 \mathrm{~mm}$ through a funnel at an angle of $45^{\circ}$. Determinations were made in triplicate. The relative density $D_{0}$ of each formulation was obtained from the ratio of the loose density to its particle density.

\section{Preparation of tablets}

A Carver hydraulic hand press (Model C, Carver Inc, Menomonee Falls, Wisconsin, U. S. A), fitted with a pressure gauge reading up to 2.5 metric tonnes was used.

Granules of size fraction $500-1,000 \mu \mathrm{m}$ were used to prepare $400 \mathrm{mg} \pm 10 \mathrm{mg}$ tablets using a $10.5 \mathrm{~mm}$ diameter die in combination with flat faced upper and lower punches. Before each compression, the punches and die were lubricated by brushing with $2 \% \mathrm{w} / \mathrm{v}$ dispersion of magnesium stearate in ethanol - ether (1:1). After ejection, the tablets were stored over silica gel for $24 \mathrm{hr}$ before tablet properties were determined, to allow for elastic recovery and hardening and prevent false low yield values.

The weights $(w)$ of the tablets were accurately determined at room temperature to within $\pm 1 \mathrm{mg}$ while the diameter and thickness of the tablets were accurately measured to within \pm $0.01 \mathrm{~mm}$.The relative densities $D$, of the tablets were calculated from the equation:

$$
D=w / V_{t} \cdot \rho_{s}
$$

where $V_{t}$ is the volume of tablet $\left(\mathrm{cm}^{3}\right)$ and $\rho_{s}$ is the particle density of the solid material $\left(\mathrm{g} / \mathrm{cm}^{3}\right)$.

\section{Crushing strength and friability tests}

Ten tablets from each formulation were tested for diametrical crushing test using the Erweka TBH 28 hardness tester (Apparatebau, $\mathrm{GMBH}$, Germany). Measurements were made in triplicate on individual tablets and the crushing strength results were accepted only if the samples split cleanly into two halves. The friability of the tablets was also determined using the Veego tablet friability apparatus (Veego Scientific Devices, Mumbai, India) at a speed of 25rpm for 4 minutes.

\section{Disintegration test}

The disintegration times of the tablets were determined in distilled water at $37^{0} \pm 0.5^{\circ} \mathrm{C}$ using the Apex disintegration testing Apparatus (Apex Construction Ltd; Northflect Gravescent and Dartford, Kent,U.K).

Tablets were placed on the wire mesh just above the surface of the water in the tube and the apparatus was started simultaneously with a stop clock. The tablets were kept in contact with distilled water contained in the tube. The time taken for all the tablets to disintegrate and go through the wire mesh was recorded. Determinations were made in triplicate.

\section{Dissolution test}

The dissolution rate of the tablets was determined in distilled water using the Rotating Basket (USP Apparatus I) method. Each tablet was placed in a cylindrical basket of stainless wire mesh attached to a variable speed drive mechanism and suspended in a glass vessel 
Itiola et al

TABLE 1: Parameters Obtained From Density Measurements and Heckel And Kawakita Plots

\begin{tabular}{llllllll}
\hline & & \multicolumn{3}{c}{ Heckel Plots } & \multicolumn{3}{c}{ Kawakita Plots } \\
\hline Starch & $\begin{array}{l}\text { Binder } \\
\text { conc. (\% w/w) }\end{array}$ & $\mathbf{D}_{\mathrm{o}}$ & $\begin{array}{l}\mathbf{P}_{\mathrm{y}} \\
\left(\mathbf{M N} / \mathbf{m}^{2}\right)\end{array}$ & $\mathbf{D}_{\mathrm{A}}$ & $\mathbf{D}_{\mathrm{B}}$ & $\mathbf{P}_{\mathbf{k}}$ & $\mathbf{D}_{\mathrm{i}}$ \\
& 0.0 & 0.276 & 95.56 & 0.863 & 0.587 & 3.212 & 0.424 \\
\multirow{3}{*}{ Trifoliate yam } & 2.5 & 0.346 & 114.21 & 0.772 & 0.426 & 2.661 & 0.410 \\
& 5.0 & 0.387 & 111.12 & 0.802 & 0.415 & 2.583 & 0.403 \\
& 7.5 & 0.392 & 96.91 & 0.800 & 0.408 & 2.449 & 0.397 \\
Corn Starch & 2.5 & 0.357 & 90.81 & 0.783 & 0.401 & 2.385 & 0.362 \\
& 10.0 & 0.284 & 142.86 & 0.830 & 0.546 & 2.889 & 0.339 \\
& 5.0 & 0.281 & 125.10 & 0.823 & 0.542 & 2.770 & 0.321 \\
& 7.5 & 0.278 & 121.41 & 0.817 & 0.539 & 2.685 & 0.318 \\
& 10.0 & 0.261 & 97.62 & 0.793 & 0.532 & 2.496 & 0.299 \\
\hline
\end{tabular}

containing $900 \mathrm{mls}$ of distilled water which was immersed in a water bath set at $37^{\circ} \pm 0.5^{\circ} \mathrm{C}$.

The apparatus was set to rotate at 100rpm and was started simultaneously with a stop clock. $5 \mathrm{ml}$ samples of the dissolution medium was removed at designated intervals and replaced with an equal volume of fresh sample of dissolution medium. The absorbance of the removed samples was measured and the total concentration of drug in each sample was determined using a UV spectrophotometer (SP6450 UV/VIS spectrophotometer, Pye Unicam, Middlesex, England)

\section{Statistical analysis}

Statistical analysis was done to compare the effect of trifoliate yam starch and corn starch on tablet properties using the $t$-test. At $95 \%$ confidence interval, $p$ value lower or equal to 0.05 was considered the limit of significance.

\section{RESULTS AND DISCUSSION}

Fig. 1 shows representative Heckel plots for chloroquine phosphate formulations containing $5 \% \mathrm{w} / \mathrm{w}$ binder. The mean yield pressure, $P_{y}$, was calculated from the regions of the plots showing linearity with correlation coefficient of $\geq 0.990$ for all formulations (generally between 56.62 and $198.16 \mathrm{MNm}^{2}{ }^{2}$ ). The intercept $A$ was determined from the extrapolation of the region used for the determination of $P_{y}$. The intercept represented the point at which a coherent or intact tablet was just formed during compression. The values of $D_{A}$ and $D_{B}$ were calculated from Eqn. 2 and 3 respectively. The values of $P_{Y}, D_{O}, D_{A}$, and $D_{B}$ for the formulations are presented in Table 1.

The values of $D_{0}$ for the various formulations increased with binder concentration, implying that the initial packing of the formulation as a result of die filling increased with increase in binder content. These values were found to be higher for formulations containing trifoliate yam starch. 
Itiola et al

Table 2. Crushing strength, friability and crushing strength-friability ratio (csfr) for chloroquine phosphate tablets at relative density 0.90

\begin{tabular}{llllr}
\hline Starch & $\begin{array}{l}\text { Binder } \\
\text { conc. }(\% \mathrm{w} / \mathrm{w})\end{array}$ & $\begin{array}{l}\text { Crushing strength } \\
(\mathrm{N})\end{array}$ & $\begin{array}{l}\text { Friability } \\
(\%)\end{array}$ & CSFR \\
\hline \multirow{2}{*}{ Trifoliate yam } & 0.0 & $34.31 \pm 2.10$ & $3.83 \pm 0.04$ & 8.95 \\
& 2.5 & $73.50 \pm 1.22$ & $2.37 \pm 0.02$ & 31.01 \\
& 5.0 & $78.41 \pm 1.02$ & $1.33 \pm 0.03$ & 58.95 \\
& 7.5 & $83.33 \pm 2.13$ & $0.83 \pm 0.02$ & 100.36 \\
& 10.0 & $88.21 \pm 1.03$ & $0.63 \pm 0.03$ & 140.00 \\
& 2.5 & $53.92 \pm 1.21$ & $2.41 \pm 0.06$ & 22.37 \\
& 5.0 & $56.41 \pm 2.01$ & $1.40 \pm 0.02$ & 40.29 \\
& 7.5 & $58.82 \pm 2.14$ & $0.96 \pm 0.05$ & 61.25 \\
& 10.0 & $44.10 \pm 1.17$ & $0.78 \pm 0.02$ & 56.54 \\
\hline
\end{tabular}

The mean yield pressure $P_{y}$ is inversely related to the ability of a material to deform plastically when compressed. The values of $\mathrm{P}_{\mathrm{y}}$ decreased with increase in binder concentration, with formulations containing trifoliate yam starch having lower values compared to corn starch. This implies that the onset of plastic deformation in the formulations containing trifoliate yam starch was faster than those containing corn starch.

Fig. 2 shows representative Kawakita plots for chloroquine phosphate formulations containing $5 \% \mathrm{w} / \mathrm{w}$ binders. A linear relationship was obtained at all compression pressures employed with a correlation coefficient $\geq 0.999$ for all formulations. Values of $a$ and $a b$ were obtained from the slope and intercept of the plots, respectively. Values of 1-a give the initial relative density, $D_{l}$, of the formulations, while $P_{k}$ values were obtained from the reciprocal of values of $b$. Values of $P_{k}$ and $D_{1}$ are included in Table I.

The $D_{1}$ values decreased with concentration of starch binder in all formulations, with formulations containing trifoliate yam starch having lower values than corn starch formulations. The $D_{1}$ values are also observed to be higher than the corresponding values of loose initial relative density $D_{0}$. Hence, these results suggest that $D_{1}$ values provide a measure of the packed initial relative density of the formulations on application of small pressure or tapping in contrast to that of $D_{0}$, which provide a measure of loose initial relative density due solely to die filling ${ }^{17}$. 
Table 3. Disintegration and dissolution characteristics of chloroquine phosphate tablets At relative density 0.90 (mean $\pm \mathrm{sd}, \mathrm{n}=4$ )

\begin{tabular}{lllllll}
\hline Starch & $\begin{array}{l}\text { Binder } \\
\text { conc. } \\
(\% \text { w/w) }\end{array}$ & $\begin{array}{l}\mathbf{D} \\
(\mathbf{m i n})\end{array}$ & $\begin{array}{l}\mathbf{t}_{\mathbf{8}} \\
(\mathbf{m i n})\end{array}$ & $\begin{array}{l}\mathbf{t}_{\mathbf{1}} \\
(\mathbf{m i n})\end{array}$ & $\mathbf{k}_{\mathbf{1}}$ & $\mathbf{k}_{\mathbf{2}}$ \\
\hline \multirow{3}{*}{ Trifoliate yam } & 0.0 & $3.83 \pm 1.01$ & $38.25 \pm 0.95$ & $34.14 \pm 1.05$ & $0.044 \pm 0.012$ & $0.134 \pm 0.031$ \\
& 2.5 & $5.03 \pm 0.22$ & $44.12 \pm 1.25$ & $31.25 \pm 0.24$ & $0.054 \pm 0.001$ & $0.237 \pm 0.021$ \\
& 5.0 & $7.02 \pm 0.15$ & $46.28 \pm 0.85$ & $33.62 \pm 0.15$ & $0.052 \pm 0.014$ & $0.126 \pm 0.014$ \\
& 7.5 & $8.53 \pm 1.02$ & $58.03 \pm 3.21$ & $41.66 \pm 0.13$ & $0.041 \pm 0.003$ & $0.085 \pm 0.002$ \\
Corn Starch & 10.0 & $9.04 \pm 0.16$ & $61.52 \pm 2.47$ & $46.72 \pm 0.52$ & $0.029 \pm 0.008$ & $0.063 \pm 0.120$ \\
& 2.5 & $5.01 \pm 0.14$ & $40.14 \pm 0.27$ & $29.42 \pm 0.14$ & $0.036 \pm 0.001$ & $0.123 \pm 0.005$ \\
& 5.0 & $6.55 \pm 0.75$ & $42.18 \pm 1.19$ & $31.86 \pm 0.75$ & $0.033 \pm 0.003$ & $0.103 \pm 0.001$ \\
& 7.5 & $7.02 \pm 0.45$ & $45.63 \pm 2.02$ & $36.07 \pm 0.98$ & $0.029 \pm 0.015$ & $0.062 \pm 0.210$ \\
& 10.0 & $9.51 \pm 0.18$ & $47.86 \pm 1.14$ & $38.22 \pm 0.17$ & $0.018 \pm 0.001$ & $0.059 \pm 0.004$
\end{tabular}

Values of $P_{k}$, which are an inverse measure of the amount of plastic deformation occurring during the compression process ${ }^{17}$, also decreased with starch concentration. Formulations containing Trofoliate yam starch had lower values than those containing corn starch. This implies that formulations containing corn starch exhibited a lower degree of total plastic deformation during the compression process. Hence, it would appear that formulations containing trifoliate yam starch exhibited a faster onset of plastic deformation during compression as indicated by the low $\mathrm{P}_{y}$ values, and also exhibited a higher degree of plastic deformation during the compression process.

There were no clear cut patterns to the variation of the values of $D_{O}, D_{B}$ and $D_{A}$ with binder concentration. However, the values of $D_{0}$ (packing during die filling) for formulations containing yam starch were significantly $(P<0.001)$ higher than for those containing corn starch. While, the values of $D_{B}$ (densification at low pressures) for formulations containing corn starch were significantly $(P<0.001)$ higher than those of formulations containing yam starch. In addition, the total degree of packing $\left(D_{A}\right)$ achieved was significantly $(P<0.05)$ higher form formulations containing corn starch. Thus, formulations containing corn starch exhibited more packing of particles before a coherent tablet was formed during compression.

The mechanical properties of the tablet formulations were assessed by the crushing strength and friability of the tablets. While crushing strength indicates the strength of the tablet, friability values provide a measure of tablet weakness. Table 2 presents values of crushing strength and friability for all formulations at a relative density of 0.90 , which is representative of commercial tablets. There was increase in crushing strength with corresponding decrease in friability values with binder concentration for all formulations. It has been established that the presence of high concentration of plasto-elastic binding agent leads to an increase in plastic deformation of the formulation and consequently to the formation of more solid bonds with increase in tablet strength and resistance to fracture and abrasion. Formulations containing the experimental starch had higher crushing strength values which could be due to the lower $P_{k}$ values which indicate greater total plastic deformation during compression.

The crushing strength-friability ratio (CSFR) also provides a parameter for measuring tablet strength ${ }^{17}$. Generally, the higher the CSFR value, the stronger the tablet. The CSFR values for all formulations are included in Table 2. An increase was observed for the tablets with increase in binder concentration, with tablets containing trifoliate yam starch showing significantly $(p<0.05)$ higher values than tablets containing corn starch.

The disintegration time values for the tablets at relative density of 0.90 are presented in Table 3. An increase was observed in disintegration time with increase in binder concentration for all formulations, although there 
Itiola et al
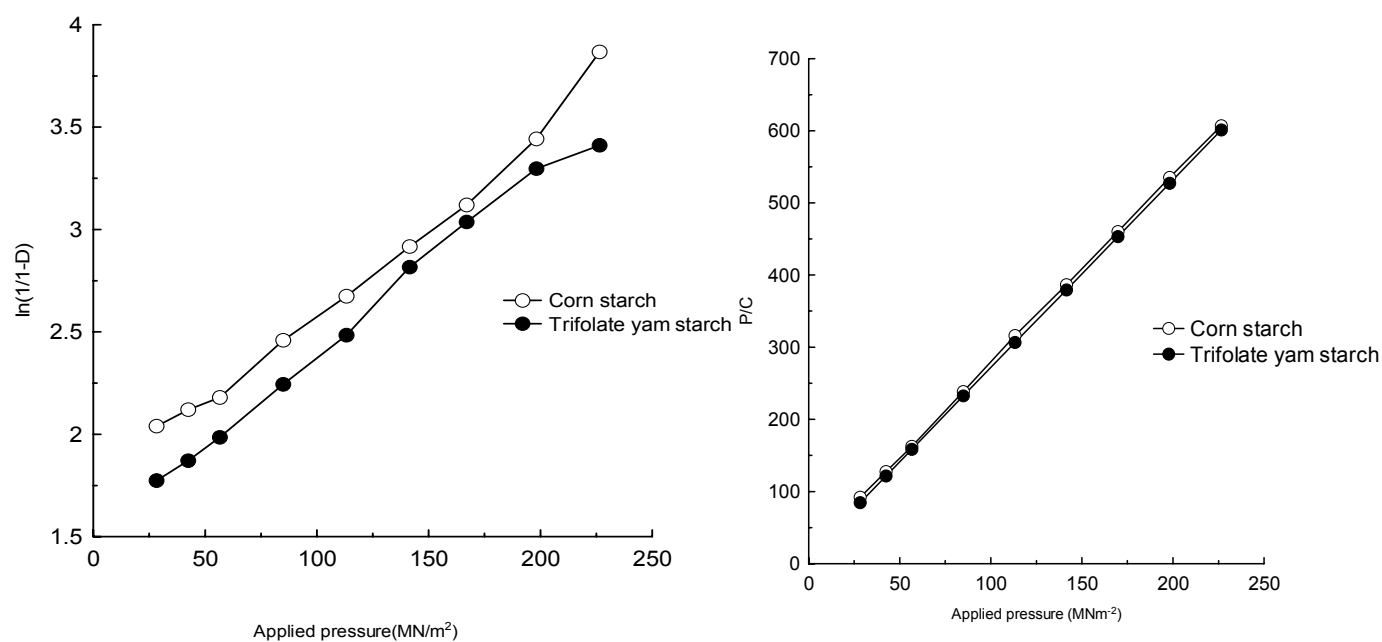
Fig 1.: Heckel plots for chloroquine phosphate tablets containing
$5 \%$ w/w starch as binder

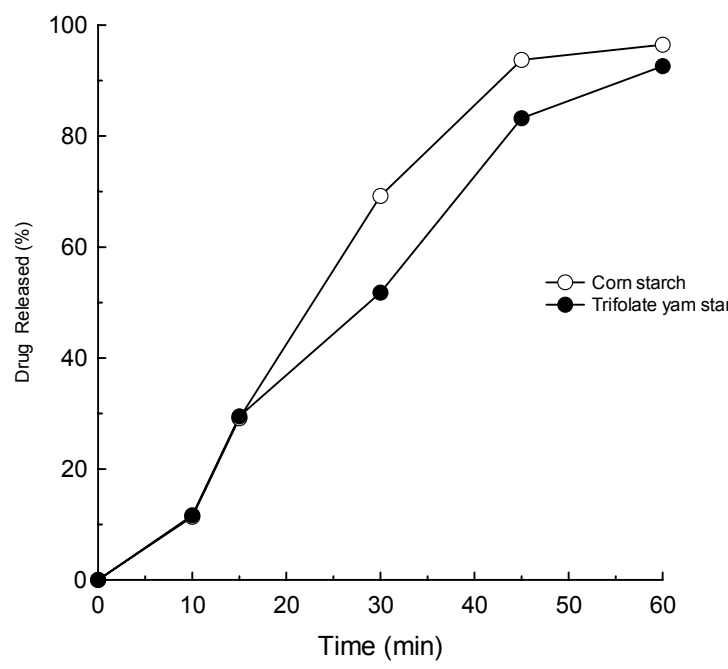

Fig. 2: Kawakita plots for chloroquine phosphate tablets containing $5 \% \mathrm{w} / \mathrm{w}$ starch as binder

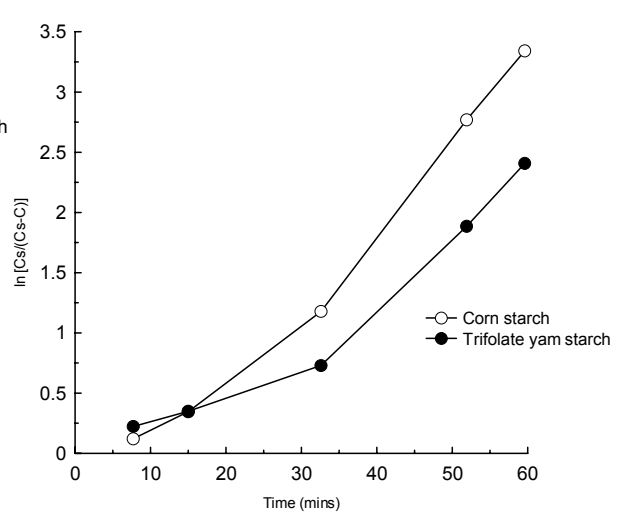

Figure 3: Dissolution plot for chloroquine phosphate released vs. time for tablets containing $5 \% \mathrm{w} / \mathrm{w}$ binder

Figure 4: In [Cs/(Cs-c)] vs. time for chloroquine phophate tablets containing $5 \% \mathrm{w} / \mathrm{w}$ starch as binder

were no significant $(p>0.05)$ differences in disintegration time between the formulations. However, all tablets passed the British Pharmacopoeia specifications for disintegration of uncoated tablets within 15 minutes.

Fig. 3 shows representative plots of the amount of chloroquine phosphate released against time for tablets containing $5 \% \mathrm{w} / \mathrm{w}$ binder. The values of $t_{80}$ (time taken for $80 \%$ of the drug to be released) were calculated. These

values for all formulations at a relative density of 0.90 are presented in Table 3 . The $t_{80}$ values increased with binder concentration for all tablets with trifoliate yam starch formulations showing higher values than those containing corn starch.

The data obtained was further subjected to Kitazawa et al. ${ }^{18}$ analysis which involves the integrated form of the Noyes-Whitney equation ${ }^{19}$ written as 
$\ln [C s /(C s-C)]=k t$

where $C_{s}$ is the concentration of the solute at saturation, $C$ is the concentration at time $t$, and $k$ is dissolution rate constant. Values of $\ln \left[C_{s} /\left(C_{s}-C\right)\right]$ were plotted versus $t$ and shown for tablets containing $5 \% \mathrm{w} / \mathrm{w}$ of binder in Figure 4.

The Kitazawa plots generally showed two straight regression lines of slopes $\mathrm{K}_{1}$ and $\mathrm{K}_{2}$. The time at which the lines intersect is denoted $t_{1}$. Values of $k_{1}, k_{2}$ and $t_{1}$ for all samples at relative density, $D$ of 0.90 are presented in Table 3. The Table shows $k_{1}$ to be lower than $k_{2}$ implying that the dissolution rate of the drug was faster after $t_{1}$. It would appear that changes in surface area of the dissolving particles brought about by the disintegration and de-aggregation of the tablets were manifested in the substantial increase in dissolution rate after $t_{1}$. Values of $t_{1}$, $k_{1}$ and $k_{2}$ for formulations containing trifoliate yam starch were higher than those for formulations containing corn starch.

\section{CONCLUSION}

The results of the present study show that trifoliate yam starch as a binder in chloroquine phosphate tablets provides faster onset and higher amount of total plastic deformation under compression pressure than corn starch. Trifoliate yam starch also produced tablets with stronger mechanical properties and longer disintegration and dissolution times than corn starch BP. The results suggest that trifoliate yam could be useful as a binding agent when a requirement of high mechanical strength is more essential.

\section{References}

1. Nasipuri RN. Evaluation of yam starch as binder and disintegrant Part I - before storage. Nig. J. Pharm .1979;10: 182-187.

2. Jaiyeoba $K T$, Spring MS. The granulation of tertiary mixtures containing lactose and boric acid with different starches. J. Pharm Pharmacol.1980; 32:386.

3. Weirik GHP, Bergsma J, Arends-Scholte A.W, Boersma J, Eissens A.C, Lerk CF. A new generation of starch products as excipients in pharmaceutical tablets. Int. J. Pharm.1996; 134:27-36.
4. Esezobo S, Ambujam V. An evaluation of starch obtained from plantain (Musa paradisiaca) as a binder and disintegrant for compressed tablets. Journal of Pharmacy and Pharmacology.1982; 34,761 .

5. Alebiowu G, Itiola OA. Effects of natural and pregelatinized sorghum, plantain and corn starch binders on the compressional characteristics of paracetamol tablet formulations. Pharm. Tech. 2001.26-30. (Suppl Ed.: Drug Delivery).

6. Alebiowu G, Itiola OA. Compressional characteristics of native and pregelatinized sorghum, plantain and corn starches and the mechanical properties of their tablets. Drug Dev. Ind.Pharm. 2002; 28 :(6) 663-672.

7. Odeku OA., Itiola OA, .Adeniran A.A. Effects of Yam and Corn Starches on the Mechanical and Disintegration Properties of Paracetamol Tablets.1st International Workshop on Herbal Medicinal Products; November 22-24, 1998; University of Ibadan, Nigeria: Omoade Printing Press. 1998, 193-200.

8. Esezobo S, Zubair S, Pilpel N. Effects of Tapioca Obtained from Cassava (Manihot utilissima) on the Disintegration and Dissolution Rates of Paracetamol Tablets. J. Pharm. Pharmacol. 1989; 41:1, 7-10.

9. Itiola OA. Compressional Characteristics of three starches and the mechanical properties of their tablets. Pharm. World J. 1991; 8:3, 91-94.

10. Heckel RW. Density-Pressure Relationships in Powder Compaction.T.Metall Soc. AIME. 1961a; 221: 671675.

11. Heckel, RW. An analysis of powder pompaction phenomena. T.Metall Soc. AIME 1961b; 221: 1001-1008.

12. Adebayo AS, Itiola, OA. (. Evaluation of Breadfruit and Cocoyam Starches as Exodisintegrants in a Paracetamol Tablet Formulation. Pharm. Pharmacol. Commun. 1998; 4: 6, 385-389.

13. Kawakita $K$, Ludde $K H$. Some considerations on powder Compression Equations. Powder Technol. 19701971; 4: 2, 61-68

14. Shivanand $P$, Sprockel, OL. Compaction behaviour of cellulose polymers. Powder Technol. 1992;.69: 2, 177-184.

15. Lin C, Cham T. Compression Behaviour and Tensile Strength of Heat-Treated Polyethylene Glycols," Int. J. Pharm. 1995; 118:2, 169-179.

16. Odeku OA, Itiola OA. (1998). Evaluation of Khaya Gum as a Binder in a Paracetamol Tablet Formulation. Pharm. Pharmacol. Commun. 4,183-188.

17. Odeku OA., Itiola OA.. Evaluation of the effects of khaya gum on the mechanical and release properties of paracetamol tablet formulation. Drug Dev. Ind. Pharm., 2003; 29: 311-320.

18. Kitazawa S, Johno I, Ito $Y$, Teramura $S$ and Okada J. Effects of hardness on the disintegration and dissolution rate of uncoated caffeine tablets. $J$ Pharm Pharmacol 1975; 27: 765-770.

19. Noyes A. A, Whitney WR. The rate of solution of solid substances in their own solutions. J. Am. Chem. Soc. 1897; 19: 930-934. 